\title{
Reproductive health experts warn women not to abandon birth control
}

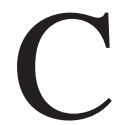

anadian medical experts fear women will stop taking birth control pills and become pregnant if they abandon the popular oral contraceptives Yaz and Yasmin amid reports of deaths and class-action lawsuits.

"There is a lot of angst out there," says Douglas Black, president of the Society of Obstetricians and Gynaecologists of Canada. "If we all of a sudden have hundreds and thousands of women coming off the pill, then we are going to see an increase in the birth rate."

Increasingly, drospirenone andethinyl estradiol, commonly known as Yaz and Yasmin, have become the problem children of the birth control market in Canada and around the world, sparking regulatory reviews, legal action, and even a ban in France.

In Canada, recent revelations that between late 2007 and February 2013, 23 girls and women died while taking Yaz or Yasmin mostly as a result of blood clots in the brain or lungs, have revived an ongoing media backlash against the pills, says Black. A 14-year-old girl was among those who died, as were at least eight other teenagers, records supplied by Health Canada show.

Canadian women taking birth control pills, including Yaz and Yasmin, should "stay the course" or consult their doctors if they are considering a change in contraception methods, Black urges.

The society, echoing Health Canada and drug-manufacturer Bayer, asserts there have always been well-known risks of blood clots associated with birth control pills, and that the benefits of Yaz and Yasmin outweigh the potential dangers.

In fact, the risk of developing blood clots is significantly greater during pregnancy than while taking oral contraceptives, including Yaz and Yasmin, says Roger Pierson, director of the Reproductive Biology Research Unit at the University of Saskatchewan.

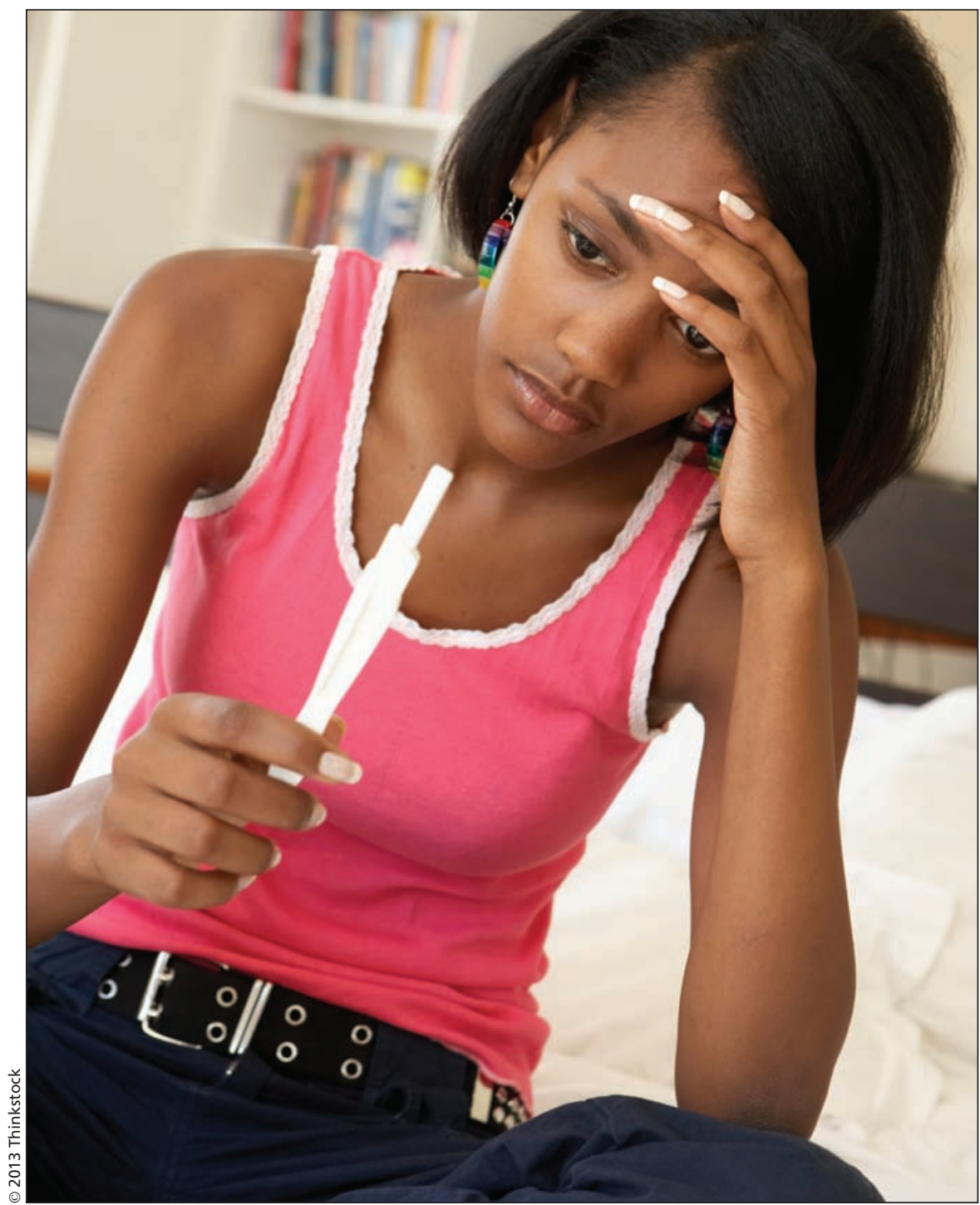

The Society of Obstetricians and Gynaecologists of Canada is concerned that if hundreds and thousands of women suddenly stop taking the pill, there will be a spike in the birth rate.

"To not take the pill puts you at a much greater risk," says Pierson. He added that there is "no reason for concern" about Yaz and Yasmin in particular, given that the health danger is still relatively low.

Yaz and Yasmin, approved in Canada in 2008 and 2004 respectively, are among a newer generation of oral contraceptives that contain the hormone drospirenone. The contraceptives are popular among young women because they also treat acne.

Black and Pierson argue the death statistics are what one would expect, given the popularity of Yaz and Yasmin, and that the chance of dying is still extremely slim, compared to other medications and activities.

Class-action lawsuits against Bayer about Yaz and Yasmin have been initiated in nine provinces since 2009. The 
lawsuits need judicial approval to proceed, which happened for the first time in April, when an Ontario judge certified a suit filed in the province in 2010 .

The crux of the case, says lawyer Matthew Baer, is that women were not properly warned that Yaz and Yasmin posed a greater risk than other oral contraceptives. He said that his office, based in London, Ont., has heard from 1300 women who have suffered adverse effects from the two pills.

"Basically the class action comes down to that there was never really any warning given that there are higher risks for Yaz and Yasmin and that's something people need to be aware of," says Baer. "If I was a woman, and I was choosing a contraceptive, I wouldn't take the one that said 'This one's an even greater risk'."

Bayer, which is fighting the Ontario certification in court, "fully stands behind" its products, spokeswoman Marija Mandic said in a written state- ment. Yaz and Yasmin, she added, are "among the most systematically studied and widely used medical products available today." The company estimated in court earlier this year that 270000 to 300000 women in Ontario have been prescribed the oral contraceptives.

The class-action certification, which Bayer is challenging in court, follows settlements in the United States, where so-called "Yaz lawyers" have collectively secured more than US\$500 million, or an average of US\$212000 each, for clients who suffered adverse reactions, according to the website of the class-action firm Ketterman, Rowland \& Westland.

There are contradictory medical studies worldwide on whether Yaz and Yasmin carry a greater risk of side effects, including death, than other oral contraceptives.

Health Canada, which reviewed several studies on Yaz and Yasmin, reported in December 2011 that the body of cur- rent evidence suggests that the risk of blood clots is 1.5 to 3 times higher with oral contraceptives that contain drospirenone compared with oral contraceptives that don't.

"The risk of blood clots with these products is well known, and is included in the drug label," Health Canada spokeswoman Leslie Meerburg wrote in an email. Health Canada ordered the label warning as a result of its review.

The US Food and Drug Administration (FDA) has reported similar risks associated with Yaz and Yasmin, based on a review of medical histories of 800000 women.

Earlier this year, France determined that the dangers outweighed the benefits and said its public drug plan would no longer cover prescription costs for women taking oral contraceptives containing drospirenone. - Janice Tibbetts, Ottawa, Ont.

CMAJ 2013. DOI:10.1503/cmaj.109-4529 